\title{
Impact of Parity on Obesity: A Cross-Sectional Study in Iranian Women
}

\author{
Mahmoud Hajiahmadi ${ }^{a}$ Hamid Shafi ${ }^{b}$ Mouloud Agajani Delavar ${ }^{c}$ \\ Departments of a Social Medicine and Health, ${ }^{b}$ Surgery and ${ }^{\mathrm{c} M i d w i f e r y, ~ F a t e m e z a h r a ~ I n f e r t i l i t y ~ a n d ~ R e p r o d u c t i v e ~}$ \\ Health Research Center, Babol University of Medical Sciences, Babol, Iran
}

\section{Key Words}

BMI · Pregnancy $\cdot$ Women's health

\begin{abstract}
Objective: The aim of the present study was to analyze whether or not parity influenced the prevalence of obesity in both pre- and postmenopausal women. Subjects and Methods: A cross-sectional study was conducted on characteristics of urban women regarding parity. A total of 1,620 women aged 45-63 years were selected using cluster sampling. A face-to-face household interview was conducted by trained, skillful personnel. A risk factor questionnaire was used to obtain information on reproductive history and sociodemographic factors. Statistical associations between parity and obesity using logistic regression were then investigated. Results: The mean BMI was $29.1 \pm 5.1$, and $96.8 \%$ of the sample population were parous, with a median of 4 births. Of the total women enrolled, $216(13.3 \%)$ had $<3$ parities, while $1,404(86.7 \%)$ had $\geq 3$ parities. The prevalence of obesity (BMI $\geq 30$ ) was $38.3 \%$, diagnosed at a mean age of $51.4 \pm 5.2$ years. After adjustment for a range of potential confounders (age, marital status, employment, education, smoking status, abortion history, savings situation and menopausal status), women with $\geq 3$ parities were at higher risk of being obese (OR 1.74, 95\% Cl 1.24-2.45; $\mathrm{p}=0.001$ ).
\end{abstract}

Conclusion: A positive association was observed between the number of parities and obesity. The findings of this study suggest that the BMI is associated with high parity in Babolian women. Health policymakers should work with health providers to develop appropriate postpartum weight loss interventions.

(c) 2014 S. Karger AG, Basel

\section{Introduction}

Obesity is a serious health concern in both developed and underdeveloped countries; it is associated with dyslipidemia, type 2 diabetes and hypertension, and elevated risk of morbidity and mortality [1-3]. Obesity plays a central role in coronary heart disease risk factors [4]. Pregnancy may be considered as having a permanent effect on BMI and may promote weight gain, hypertension, dyslipidemia and insulin resistance in later life [5].

The prevalence of obesity varies significantly across the world. It is usually more common in women than men [6]. Obesity has become a common factor among Iranian women due to lifestyle factors such as diet, lack of physical activity and adaptation to a western lifestyle. In Iran, the prevalence of obesity ( $\mathrm{BMI} \geq 30$ ) is $28.0 \%$ [7], but in a recent survey in the city of Babol, the overall preva-

\begin{tabular}{ll}
\hline KARGER 125:s & $\begin{array}{l}\text { () 2014 S. Karger AG, Basel } \\
1011-7571 / 14 / 0241-0070 \$ 39.50 / 0 \quad \text { Karger }\end{array}$ \\
$\begin{array}{l}\text { E-Mail karger@karger.com } \\
\text { www.karger.com/mpp }\end{array}$ & $\begin{array}{l}\text { This is an Open Access article licensed under the terms of the } \\
\text { Creative Commons Attribution-NonCommercial 3.0 Un- } \\
\text { ported license (CC BY-NC) (www.karger.com/OA-license), } \\
\text { applicable to the online version of the article only. Distribu- } \\
\text { tion permitted for non-commercial purposes only. }\end{array}$
\end{tabular}

Mouloud Agajani Delavar

Department of Midwifery

Babol University of Medical Sciences

Babol 4717647745 (Iran)

E-Mail moloodaghajani@yahoo.com 
lence of obesity was $45.0 \%$ among middle-aged women [8].

Several studies have revealed that some women may be especially prone to obesity following pregnancy due to the natural process of weight cycling, the accumulation of fat or a high maternal metabolism during the postpartum period. Pregnancy and childbearing are causes of obesity in women during reproductive years [9-12]. Given this evidence, it is likely that a positive association between gestational weight gain and postpartum body weight exists. Little is known about the relationship between parity and the risk of obesity in later life among women living in developing countries. Therefore, the present study investigated the relationship between parity and BMI in Babol, Iran, among highly parous women in later life.

\section{Subjects and Methods}

This study was approved by the Ethics Medical Research Committee of Babol University of Medical Sciences. Based on the geographical area, 60 clusters in Babol were selected according to the list of census enumeration areas with population and household information from the 2009 population census. The primary sampling unit for this study was based on a ward in urban and periurban areas of the city. At the second stage of sampling, an average of 27 households per primary sampling unit in urban areas was selected. A starting household was randomly selected in each cluster. After that, one household after the other was surveyed until the entire selected cluster of 1,620 was done. Exclusion criteria were a history of renal or thyroid dysfunction, acute hepatitis, and acute or chronic joint diseases. Otherwise, inclusion criteria were women aged 45-65 years who had the ability to understand a Persianlanguage questionnaire with the help of an interviewer.

Written informed consent was obtained from all participants in the study. A face-to-face household interview was conducted by a trained, skillful coauthor (M.A.D.). A valid and reliable questionnaire of risk factors was used to obtain information on reproductive history (age at menarche, gravidity, parity, abortion history and menopausal status) and sociodemographic factors, such as age, height, weight, marital status, education, occupation and savings situation.

Parity data or the number of full-term pregnancies were collected using the interview-administered questionnaire. The study population was divided into two groups according to parity. Parity was considered as any pregnancy lasting longer than 20 weeks and summarized as $<3$ and $\geq 3$ pregnancies.

The weight of each subject was recorded using digital scales to the nearest $100 \mathrm{~g}$, with the participant minimally clothed and without shoes. Height was measured with a tape measure [13], and the BMI was calculated as weight divided by height squared $\left(\mathrm{kg} / \mathrm{m}^{2}\right)$ [14].

All analyses were performed with SPSS software (version 16.0; SPSS, Chicago, Ill., USA). The difference in the distribution of the women by parity for sociodemographic characteristics, smoking, reproductive and BMI variables were tested by mean and $\chi^{2}$ test.

Impact of Parity on Obesity in

Middle-Aged Women
The mean BMI (with 95\% confidence intervals, CIs) was reported for the categories of parity and other factors where appropriate. Measurement variables for the $<3$ and $\geq 3$ parity groups were compared using the $t$ test. The multiple logistic regressions were used to determine the effect of factors that are associated with obesity. The odds ratios (OR) are presented together with 95\% CIs.

The following potential confounders were included in the statistical models for the main analyses: age (continuous variable), marital status (married or not), education (less than elementary level or at least elementary level), occupation (housewife or employed), menopausal status and economic status (a combination of variables, including occupation, education, income, and savings or no savings).

\section{Results}

Of the 1,620 participants interviewed, 1,460 completed the questionnaire, representing a $90.1 \%$ response rate. The mean values $( \pm \mathrm{SD})$ for the total population were: weight $71.0 \pm 12.6 \mathrm{~kg}$; height $156.4 \pm 5.7 \mathrm{~cm}$, and BMI $29.1 \pm 5.1$. Among married women, parity ranged from 0 to 14 , with a median of 4 births. A total of 216 (13.3\%) women had $<3$ parities, and 1,404 (86.7\%) had $\geq 3$ parities. A higher parity was reported among older women (age $\geq 50$ years), those currently married, housewives, current smokers, those that were obese, and those with a lower level of education or history of at least one abortion (table 1).

The mean BMI of the women by selected characteristics are described in table 2 . The mean BMI was greater in women who had higher parity $(\mathrm{p}=0.0001)$, were housewives $(\mathrm{p}=0.001)$, older $(\mathrm{p}=0.0001)$ or premenopausal $(\mathrm{p}=0.002)$. The prevalence of obesity $(\mathrm{BMI} \geq 30)$ was $38.3 \%$ at a mean age of $51.4 \pm 5.2$ years. The crude OR showed a strong association between parity and obesity $(\mathrm{p}=0.0001)$. After adjusting for a range of potential confounders (age, marital status, employment, education, smoking status, abortion history, menopausal status and economic status), higher parity ( $\geq 3$ pregnancies) was significantly associated with obesity (OR 1.74, 95\% CI 1.24$2.45 ; \mathrm{p}=0.001 ;$ table 3 ).

\section{Discussion}

In this study, the mean BMI of 29.1 is similar to the value of 28.6 for women aged 35-81 years in Golestan Province, northeastern Iran [7], but greater than the average of 25-27 amongst Americans and Europeans and in some Latin American, North African and Pacific Island countries, as reported by WHO [11]. The overall preva- 
Table 1. Study characteristics grouped by parity in women aged $45-63$ years

\begin{tabular}{|c|c|c|c|c|}
\hline \multirow[t]{2}{*}{ Characteristies } & \multicolumn{3}{|l|}{ Parity } & \multirow[t]{2}{*}{$\chi^{2} \mathrm{p}$ value } \\
\hline & mean $\pm S D$ & $<3(\mathrm{n}=216)$ & $\geq 3(\mathrm{n}=1,404)$ & \\
\hline Age & & & & 0.0001 \\
\hline$<50$ years & $3.9 \pm 1.6$ & $112(51.9)$ & $547(39.0)$ & \\
\hline$\geq 50$ years & $4.6 \pm 2.0$ & $104(48.1)$ & $857(61.0)$ & \\
\hline Marital status & & & & 0.0001 \\
\hline Married & $4.4 \pm 1.8$ & $174(80.6)$ & $1,299(92.5)$ & \\
\hline Single (divorced/widowed/unmarried) & $3.7 \pm 2.4$ & $42(19.4)$ & $105(7.5)$ & \\
\hline Education level & & & & 0.0001 \\
\hline Less than elementary level & $4.9 \pm 1.9$ & $65(30.1)$ & $864(61.5)$ & \\
\hline At least elementary level & $3.5 \pm 1.5$ & $151(69.9)$ & $540(38.5)$ & \\
\hline Occupation & & & & 0.0001 \\
\hline Housewife & $4.5 \pm 1.9$ & $155(71.8)$ & $1,273(90.7)$ & \\
\hline Employed & $3.2 \pm 1.4$ & $61(28.2)$ & $131(9.3)$ & \\
\hline Savings situation & & & & 0.0001 \\
\hline With savings & $3.7 \pm 1.6$ & $57(26.4)$ & $193(13.7)$ & \\
\hline No savings & $4.4 \pm 1.9$ & $159(73.6)$ & $1,211(86.3)$ & \\
\hline Smoking status & & & & 0.012 \\
\hline Smoker & $3.7 \pm 1.9$ & $6(2.8)$ & $12(0.9)$ & \\
\hline Nonsmoker & $4.3 \pm 1.9$ & $210(97.2)$ & $1,392(99.1)$ & \\
\hline Age at menarche & & & & 0.298 \\
\hline$<13$ years & $4.2 \pm 1.9$ & $61(28.2)$ & $350(24.9)$ & \\
\hline$\geq 13$ years & $4.4 \pm 1.9$ & $155(71.8)$ & $1,054(75.1)$ & \\
\hline Abortions & & & & 0.0001 \\
\hline None & $4.1 \pm 1.9$ & $157(72.7)$ & $808(57.5)$ & \\
\hline At least one & $4.7 \pm 1.9$ & $59(27.3)$ & $596(42.5)$ & \\
\hline Menopausal status & & & & 0.004 \\
\hline Premenopause & $3.9 \pm 1.6$ & $106(49.1)$ & $550(39.2)$ & \\
\hline Postmenopause & $4.6 \pm 2.0$ & $110(50.9)$ & $854(60.8)$ & \\
\hline BMI & & & & 0.0001 \\
\hline Normal or below $(<24.9)$ & $4.0 \pm 1.9$ & $59(27.3)$ & $272(19.4)$ & \\
\hline Overweight $(25.0-29.9)$ & $4.2 \pm 1.8$ & $99(45.8)$ & $568(40.5)$ & \\
\hline Obese $(\geq 30.0)$ & $4.7 \pm 1.9$ & $58(26.9)$ & $564(40.2)$ & \\
\hline
\end{tabular}

Data are presented as mean parity $\pm \mathrm{SD}$, or number with percentage in parentheses.

lence of obesity (BMI $\geq 30$ ) of $38.3 \%$ is similar to that of Mexican-American women (39.9\%) [15], lower than that of women in the Kingdom of Saudi Arabia (44\%, ageadjusted prevalence of obesity) [16], but higher than the $30.1 \%$ reported in Tehran [17].

Studies have shown a wide variability in factors that are likely to influence BMI among women, including age, maternal status, education level, age at menarche, economic status, abortion history, menopausal status, smoking status and other factors $[4,7,15,18,19]$. However, in this study we also found increased BMI in women to be associated with a higher parity, as previously reported $[9$, $18,20-22]$.
Martinez et al. [15] reported no relationship between the number of pregnancies and obesity, although they did not include nulliparous women. The mechanisms for the association between obesity and multiparity are not known, but new evidence suggests that high maternal glucose, free fatty acid and amino acid concentrations may also play a role in gestational weight gain and postpartum weight retention, thereby increasing the risk of obesity in later life $[6,15,21]$. Hence, we recommend postpartum and peripartum counseling on weight loss.

This study has several limitations. These include its cross-sectional nature and the inability to measure BMI prior to pregnancy; that physical activity status, diet 
Table 2. Mean BMI among women aged 45-63 years corresponding to selected characteristics

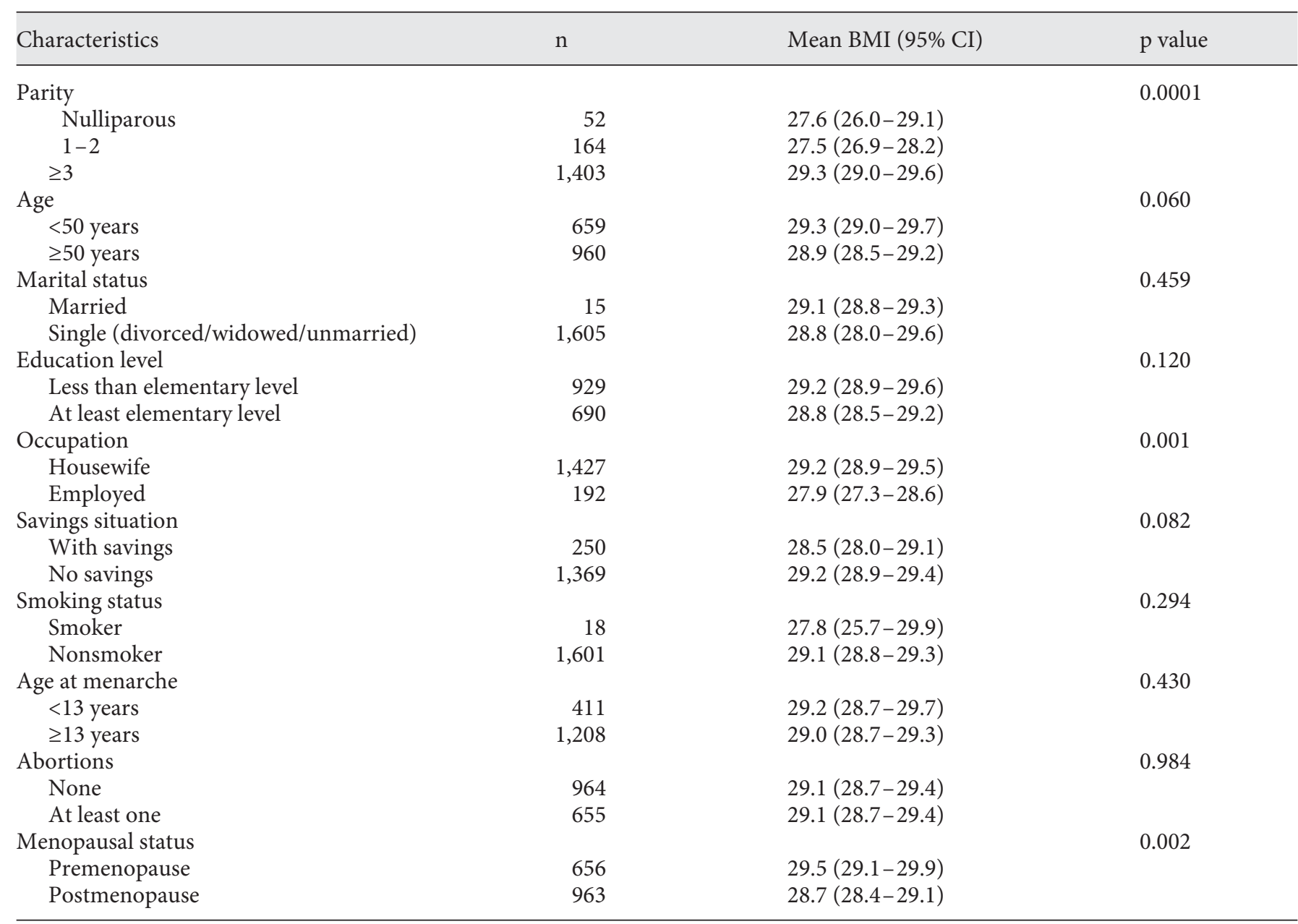

quantity and quality were not considered, and the exclusion of women with a history of renal or thyroid dysfunction. However, a strength of our study was that measurements of body weight and height were actually performed, rather than relying on the self-reporting of each participant.

\section{Conclusion}

The current study has shown that multiparity is a risk factor for obesity in later life. This information can be used widely to design public health interventions over time for supporting targeted health interventions, even for obese women either before or after menopause. Iranian health policymakers should develop an appropriate intervention plan to decrease the incidence of obesity.
Table 3. Analysis of the association of obesity with parity, occupation and menopausal status $(n=1,620)$

\begin{tabular}{llll}
\hline Characteristics & Adjusted OR & 95\% CI & p value \\
\hline $\begin{array}{l}\text { Parity } \\
\geq 3\end{array}$ & 1.77 & $1.26-2.47$ & 0.001 \\
$\quad<3$ & 1.00 & & \\
$\begin{array}{l}\text { Occupation } \\
\quad \text { Housewife }\end{array}$ & 1.70 & $1.17-2.47$ & \\
$\quad$ Employed & 1.00 & & \\
$\begin{array}{l}\text { Menopausal status } \\
\quad \text { Premenopause } \\
\text { Postmenopause }\end{array}$ & 1.23 & 0.005 & \\
$\quad 1.00$ & & \\
\hline
\end{tabular}

Adjusted for age, marital status, employment, education, smoking status, abortion history, menopausal status and economic status. 


\section{References}

$>1$ Dinc GE, Eser GL, Saatli GL, et al: The relationship between obesity and health related quality of life of women in a Turkish city with a high prevalence of obesity. Asia Pac J Clin Nutr 2006;15:508-515.

-2 Hurt RT, Edakkanambeth Varayil J, Ebbert JO: New pharmacological treatments for the management of obesity. Curr Gastroenterol Rep 2014; 16:394.

3 Babusik P, Bilal M, Duris I: Nonalcoholic fatty liver disease of two ethnic groups in $\mathrm{Ku}$ wait: comparison of prevalence and risk factors. Med Princ Pract 2012;21:56-62.

-4 Taylor JY, Chambers AN, Funnell B, et al: Effects of parity on blood pressure among African-American women. J Natl Black Nurses Assoc 2008; 19:12-19.

$\checkmark 5$ Hardy R, Mishra GD, Kuh D: Body mass index trajectories and age at menopause in a British birth cohort. Maturitas 2008;59:304314.

6 Gunderson EP: Childbearing and obesity in women: weight before, during, and after pregnancy. Obstet Gynecol Clin North Am 2009; 36:317-332.

7 Bahrami H, Sadatsafavi M, Pourshams A, et al: Obesity and hypertension in an Iranian cohort study: Iranian women experience higher rates of obesity and hypertension than American women. BMC Public Health 2006;6:158.

-8 Delavar MA, Lye MS, Khor GL, et al: Prevalence of metabolic syndrome among middle aged women in Babol, Iran. Southeast Asian J Trop Med Public Health 2009;40:612-628.
9 Davis EM, Zyzanski SJ, Olson CM, et al: Racial, ethnic, and socioeconomic differences in the incidence of obesity related to childbirth. Am J Public Health 2009;99:294-299.

$>10$ Lao XQ, Thomas GN, Jiang CQ, et al: Parity and the metabolic syndrome in older Chinese women: the Guangzhou Biobank Cohort Study. Clin Endocrinol 2006;65:460-469.

11 Farley DM, Choi J, Dudley DJ, et al: Placental amino acid transport and placental leptin resistance in pregnancies complicated by maternal obesity. Placenta 2010;31:718-724.

12 Kirkegaard H, Stovring H, Rasmussen KM, et al: How do pregnancy-related weight changes and breastfeeding relate to maternal weight and BMI-adjusted waist circumference 7 years after delivery? Results from a path analysis. Am J Clin Nutr 2014;99:312-319.

13 Craig CL, Marshall AL, Sjostrom M, et al: International physical activity questionnaire: 12-country reliability and validity. Med Sci Sports Exerc 2003;35:1381-1395.

14 Higgins D: Patient assessment. Part 1: calculation of body mass index. Nurs Times 2008; 104:24-25.

15 Martinez ME, Pond E, Wertheim BC, et al: Association between parity and obesity in Mexican and Mexican-American women: findings from the Ella binational breast cancer study. J Immigr Minor Health 2013;15: 234-243.
16 Al-Nozha MM, Al-Mazrou YY, Al-Maatouq MA, et al: Obesity in Saudi Arabia. Saudi Med J 2005;26:824-829.

17 Malekzadeh R, Mohamadnejad M, Merat S, et al: Obesity pandemic: an Iranian perspective. Arch Iran Med 2005;8:1-87.

18 Rebholz SL, Jones T, Burke KT, et al: Multiparity leads to obesity and inflammation in mothers and obesity in male offspring. Am J Physiol Endocrinol Metab 2012;302:E449_ E457.

19 Babusik P, Duris I: Comparison of obesity and its relationship to some metabolic risk factors of atherosclerosis in Arabs and South Asians in Kuwait. Med Princ Pract 2010;19: 275-280.

20 Luoto R, Mannisto S, Raitanen J: Ten-year change in the association between obesity and parity: results from the National FINRISK Population Study. Gend Med 2011;8:399406.

21 Koch E, Marshall AL, Sjostrom M, et al: Impact of parity on anthropometric measures of obesity controlling by multiple confounders: a cross-sectional study in Chilean women. J Epidemiol Community Health 2008;62:461470 .

22 Weng HH, Bastian LA, Taylor DH, et al: Number of children associated with obesity in middle-aged women and men: results from the health and retirement study. J Womens Health (Larchmt) 2004;13:85-91. 